\title{
Research on the Theoretical Explanations on the Physical Education Details and Resource Generation Strategies
}

\author{
Jinghong Guan \\ Jilin Huaqiao University of Foreign Languages, Changchun, Jilin, China
}

172858538@qq.com

Keywords: Theoretical Explanations, Physical Education Details, Resource Generation Strategies

\begin{abstract}
This paper analyzes the concept, essence, characteristics and types of PE teaching details from the theoretical level, and explores the strategy of using and regulating PE teaching details to promote PE teaching resources formation. It points out that the importance of physical education teaching should be strengthened, the unity of teaching art and wisdom of PE teachers should be promoted, the quality and efficiency of PE teaching should be improved, and the students' physique should be improved.
\end{abstract}

\section{Introduction}

Through physical education, students can enhance physical fitness, improve the health of students, promote the overall physical and mental qualities to the coordinated development of students, but also to promote the comprehensive development of moral, intellectual and physical. This is the purpose of physical education, but also the requirements of physical education. How to determine whether the physical education to meet these requirements? In order to get a better effect of physical education, we must pay attention to and do a good job of every detail of physical education. The effect of physical education teaching is determined by the details of physical education. The effect of PE teaching is good, which shows that the quality of PE teaching is high, otherwise it is not high. Therefore, the details of physical education also directly determine the quality of physical education. School as a personnel training institutions, it is the national construction and development of training, transmission of talent, the school only start with the details, the physical education can be improved in order to obtain a higher quality of teaching in order to better carry out development and reform, and Social development to adapt to the needs of qualified personnel for the community to transport high-quality talent. However, if we want to formulate a more complete teaching detail of the program, the prerequisite is to organize the physical education teaching resources and rational planning. In addition, in the process of designing the detailed plan of physical education, we should pay more attention to the study from many angles, find more scientific and reasonable teaching methods, and make the students get a better exercise experience in the process of PE teaching, Students get a comprehensive and healthy development.

\section{The Definition of the Physical Education Details}

The process of development of all things in the world is the first to produce quantitative change, and then on the basis of quantitative qualitative change. The amount is the accumulation of the volume, is a gradual process, while the qualitative change is a mutation. The state of each detail is determined by the quantitative change. There are also many details in the two-way interaction between teacher "teaching" and student "learning", which determines the success or failure of PE teaching. Therefore, it should be in the specific process of physical education, physical education to pay attention to many details.

From the existing research results, the majority of scholars based on the dictionary of the Notes and "teaching details" of the literal understanding of the definition of "teaching small links or circumstances, constitute the basic unit of teaching activities." Sports scholar and then the "details of physical education," understood as "constitute the smallest unit of physical education, behavior, teaching behavior is the specific decomposition." This definition is inevitably apparent, simplistic, 
and its essence is a concept of the definition of generalization and absolute. First, from the analysis of the main elements of physical education, physical education teaching details is the interaction between teaching and learning between the two teachers and students, while other non-teacher and student behavior cannot be included in the details of physical education. Secondly, from the point of view of the elements of physical education teaching, the details of physical education teaching is the smallest unit of teaching, but it includes various elements of physical education teaching and plays the most important role in the teaching and learning of physical education. The proper disposal of the details of physical education can have a positive impact on the whole PE classroom teaching. In addition, from the degree and nature of importance, the details of PE teaching are rooted in the PE teaching process and affect the progress of the whole PE teaching process. It is the most influential joint point, which plays an important role in the implementation of PE teaching contents. Has important teaching value. From the nature of the role of view, the details of physical education teaching the role of the process of teaching is not to promote or impede. Therefore, not all of the "small details or plot" in physical education have the characteristics of physical education teaching details, only the effect of physical education and physical education as part of the details of the physical education is the details of the teaching. That is to say with the high degree of physical education teaching the details of the details is the real physical education.

The essence of the details of physical education teaching content is to have the details of physical education with the characteristics of an accurate and comprehensive reflection. However, $\mathrm{PE}$ teaching is a kind of teaching activity. It is a process of the participation of PE teachers and students in a planned, purposeful and organized way. Therefore, the definition of details of physical education, only this as the basis for the specific details can be defined as the details of physical education. Therefore, physical education teaching details refers to the elements of physical education or physical education teaching behavior and it has a certain teaching characteristics, but also can have a certain impact on the effect of physical education. From the static point of view, the details of physical education teaching is an important component of physical education; from the dynamic point of view, physical education teaching is a basic behavior in physical education teaching and learning from the static point of view.

\section{The Basic Characteristics of the Physical Education Details}

The Intuitionistic Concrete Features of Physical Education Teaching Details. Mainly refers to the physical education teaching details can be teachers and students common perception, not abstract, including observable and understandable two aspects of the characteristics. The details of physical education teaching can be seen, heard, touched with the concrete physical education behavior. It may be a combination of physical education teachers' language, action, facial expression and interaction between teachers and students. It may also be an important behavioral response to PE teaching in specific PE teaching situations. Once the details of physical education, physical education teachers and students can easily be observed and captured. Sports teaching details directly affect the achievement of the goal of physical education, affecting the smoothness, accuracy, rationality and artistry of physical education teaching process and it is a practical means to solve the difficult and difficult points of physical education teaching. If the physical education teachers can skillfully direct and direct the details of the physical education teaching and make them better serve the PE teaching objectives, the PE teaching effect can be improved.

The Miniature Features of Physical Education Teaching Details. Refers to the details of physical education in time, space, processes and other dimensions have a short miniature features. However, the physical education teaching details are small, but in the teaching process of the key points of the physical education, education plays an important role in promoting, connecting, and continuing role, reflecting the physical education teacher instructional design, strategy and behavior of pertinence and rationality And effectiveness. Therefore, due to the miniature characteristics of physical education teaching details, it is necessary for physical education teachers to presuppose, excavate and capture the details of physical education teaching, and to optimize the regulation and control to make it better promote the realization of physical education teaching objectives. 
The Formation Characteristics of Physical Education Teaching Details. The details of physical education teaching are specific reaction behaviors in specific situations, and the occasional events generated in specific situations are very occasional and instantaneous. The wonderful details of physical education teaching are often impossible to presuppose. It is formed and produced in the specific situation of physical education teaching, formed in the interaction between teachers and students in physical education. The details of physical education teaching are the most basic part of physical education teaching. The different physical education teaching details constitute a complete physical education teaching system, which all apply to the development and realization of physical education teaching target. For each of the physical education teaching details of the default and regulation have a unique approach and approach. Therefore, the clear objectives of physical education and teaching of physical details of uncertainty must be harmonious and unified. Then it requires that physical education teachers should have a keen observation to find, capture and control the details of physical education, with the dynamic generation of thinking way of regulating physical education, wisdom and regulation of clear physical education goals and no specific details of physical education Relationship.

The Situational Characteristics of Physical Education Teaching Details. The detail of physical education teaching is a part of effective teaching means in specific situations. The details of physical education teaching are not only the microcosmic level of PE classroom teaching, but also the middle school level and even the macro level social scene. The education implication in three aspects: First, the physical education teaching includes a variety of physical education scene, physical education teachers and students are always faced with the immediate occurrence of various forms and complex structure of the dynamic changes in sports teaching details, we must adopt flexible coping strategies to optimize and solve. Second, physical education teaching in a certain situation in the details of the teaching, often with a certain degree of sociological characteristics and cultural color and by its impact, often highlighted in the relationship between teachers and students and sports teaching and cultural level. Third, the details of physical education have a certain appeal. For every teacher and student participating in the teaching of physical education, they will be infected by the details of physical education teaching. If we can timely and decisively adjust the real-time physical education teaching details, will make the physical education to a certain level of the pursuit of high-grade, will produce good physical education effect.

\section{The Classification of Physical Education Details}

Sports teaching details can be classified according to different classification criteria for a variety of different types, mainly in the following categories. (1) According to the details of physical education and its implementation of the main division, divided into: issued by the physical education, students do not need to cope with the behavior and behavior of a single physical education, such as: physical education teachers language, facial expressions; The interaction between teachers and students need to be completed; According to PE teachers require students to make the relevant reactions may be in the classroom, may also be outside the classroom, such as: after-school Technical exercises, after-school learning summary and so on. (2) According to whether it is a planned division, can be divided into: presupposition, the formation of two kinds of physical education details. For the most basic details of physical education, it can be preset. However, it cannot accurately predict all the details of physical education, which need to be adjusted according to the specific circumstances of the time, this adjusted physical education details, is the details of the formation of physical education. Through the optimization of the details can better reflect the physical education teachers teaching wisdom and teaching philosophy.

\section{The Resource Generation Strategy of Physical Education Teaching Details}

Integrate Resources and in-Depth Mine Physical Education Details. In physical education, only the rational integration and use of sports materials, and its comprehensive grasp and understanding on the basis of the physical design can be the reasonable teaching details. In this process, the 
physical education teachers must first optimize the allocation of sports materials, refining content, clear the heavy and difficult, reasonable arrangements for load, exercise density and intensity, to maximize the effectiveness of the details of physical education to create a good teaching situation, Teaching more effective.

Improve Teaching Methods and Rational Design Sports Teaching Details. Reasonable design of physical education teaching methods, there are language law, intuitive method, inquiry learning, discovery teaching method. Through a variety of teaching methods of comprehensive use, so that the enthusiasm of students can be fully mobilized, so that students can participate in physical education process wholeheartedly to achieve the purpose of physical education.

Flexibility Use the Physical Education Details. In PE teaching, the strengthening of students 'subjectivity can make the students' ability of reaction and thinking be effectively mobilized, to maximize the functions of the details of physical education in order to better achieve the purpose of physical education.

Innovate the Teaching Evaluation and Promote the Physical Education Details to be Fully Enhanced. The so-called evaluation of physical education is to compare the effect of PE teaching with the target of PE teaching and make a correct judgment on whether or not the effect is achieved. In the evaluation, physical education teachers should not only have all the resources available, but also in a proper and reasonable manner. In addition, the evaluation is not only a simple affirmative or negative, to promote the students through the evaluation of the desire to think about the problem, so that students divergent thinking, improve the ability to identify and solve problems, stimulate student motivation for innovation. To make the details of physical education to be fully upgraded, we must make a reasonable evaluation.

\section{Conclusion}

The design of PE teaching details can be used to generate PE teaching resources. PE teaching resources can promote the design of $\mathrm{PE}$ teaching details. The design of $\mathrm{PE}$ teaching details can influence the level of teaching quality, and also affect the realization of PE teaching. Therefore, it is necessary to strengthen the application of physical teaching details, improve the quality of physical education teaching to help achieve the effectiveness of physical education teaching from the true sense.

\section{References}

[1] Huifang Zhou: Journal of Wuhan Institute of Physical Education, Vol. 6 (2004) No 53, p.25-26

[2] Hongli Zhang: Modern Education, Vol. 12 (2005) No 27, p.74-76

[3] Qin Guo: Qufu Normal University, Vol. 1 (2006) No 33, p.11-14

[4] Jieming Liu: Guangxi Normal University, Vol. 3 (2007) No33, p.121-124

[5] Jia Xinzhang, Li Jingyuan. Journal of Shenyang Physical Education Institute, Vol. 6 (2014) No 53, p.25-26 